\title{
DISCURSO FILOSÓFICO Y NARRACIÓN EN JAIME RUBIO: UNA HIPÓTESIS
}

\author{
Héctor Hernando Salinas Leal * \\ doi:10.11144/Javeriana.uph33-66.dfnh
}

Una obra póstuma que forma parte de nuestra historia

COMO LECTORES, RARA VEZ TENEMOS el privilegio de sentir que una obra leída fue previamente compartida con nosotros en el espacio abierto y dinámico de la lección magistral y el seminario filosófico. Hacia una hermenéutica de nuestra conciencia histórica, obra póstuma de Jaime Rubio que hoy acogemos con alegría y gratitud, nos permite vivir esa experiencia singulary, a la vez, recordar imaginativamente ese cercano pasado de nuestra primera formación tan caro al espacio de experiencia y al horizonte de espera que constituyen nuestra historicidad y sus posibilidades.

La existencia de este libro, tal como lo vemos aquí hoy, invita ante todo a extender un sincero y cordial agradecimiento a su equipo de editores, quienes al

\footnotetext{
Pontificia Universidad Javeriana, Bogotá, Colombia.

Correo electrónico: hsalinas@javeriana.edu.co

Para citar este artículo: Salinas Leal, H.H. (2016). Discurso filosófico y narración en Jaime Rubio: una hipótesis. Universitas Philosophica, 33(66), pp. 296-308. ISSN 0120-5323, ISSN en línea: 2346-2426, doi:10.11144/Javeriana.uph33-66.dfnh

Este escrito es una versión ampliada y mejorada de mi intervención en el evento de cierre en homenaje a Jaime Rubio, con motivo del lanzamiento de su obra póstuma Hacia una hermenéutica de nuestra conciencia histórica, en el marco del XX Coloquio Interno de Profesores de la Facultad de Filosofía. Pontificia Universidad Javeriana, 7 y 8 de octubre de 2015. He mantenido en el texto el tono y el estilo de la exposición oral. El personaje (el filósofo Jaime Rubio), el lugar (la Facultad de Filosofía de la Universidad Javeriana) y la ocasión (el Coloquio de Profesores) determinaron de comienzo a fin la concepción de la exposición hasta el punto de formar parte integral del mundo que este modesto trabajo pretende compartir con sus lectores.
} 
rescatar y hacer pública la obra ${ }^{1}$, nos brindan, a unos, una nueva y pertinente ocasión de reencontrarnos en una de sus más acabadas configuraciones con el pensamiento del maestro, y a otros, la ocasión de un primer encuentro con esa voz difícil y estimulante a la vez, que da qué pensar.

Creo que para quienes fuimos alumnos de Jaime Rubio, la lectura de este texto se erige como prueba material de ese modo de concebir la filosofía como actividad creadora del pensar. En este trabajo, Rubio comparte con sus lectores potenciales la aplicación o reconfiguración de algunas de las obras que marcaron su recorrido filosófico y, con ese mismo gesto, comparte también un ejercicio de reapropiación de sí mismo. Al decir «aplicación» con Gadamer o «reconfiguración » con Paul Ricœur, digo también que se trata de la aplicación o reconfiguración de las obras de estos filósofos y de otros autores mayores de la filosofía, la historia y la literatura, en la experiencia de una conciencia histórica, la de Jaime Rubio y la nuestra, que se sabía y siempre se supo latinoamericana ${ }^{2}$. Adelantando un elemento de la lectura que propongo, diré que esta obra es un ejercicio de autocomprensión como práctica del decir, esto es, en su doble condición de recepción y creación de las obras del pasado en la vida de Jaime Rubio lector-escritor.

\section{Paul Ricœur y la teoría de la triple mímesis}

El PROYeCto REALIZADO EN esta obra es el de una antropología filosófica de raigambre hermenéutica, que concibe la comprensión de sí como comprensión de la historia personal y colectiva en la actividad transformadora de la lectura de las obras que la cultura y su tradición múltiple ofrecen al individuo y a su

1 "Esta publicación ve la luz por generosa autorización de los hijos de Jaime: Diego Rubio Fernández y Juana María Rubio Fernández, recompensada hoy con inmensa gratitud. El trabajo de edición académica - levantamiento del texto en formato digital a partir de fotocopias tomadas del original, la revisión y normalización de citas bibliográficas, la corrección de estilo y, de manera más puntual, el cambio justificado introducido en el título, a partir del empleado por el autor mismo en el VII capítulo (alterando un mínimo el informe original que reza solamente como: Hermenéutica de nuestra conciencia histórica)-, es producto del esfuerzo conjunto entre discípulos, admiradores y amigos suyos: Carlos Arturo Arias Sanabria, Anna Valentina Beltrán Sánchez, Airlen María Durán Acosta y Francisco Sierra Gutiérrez" (Arias et al., 2015, p. 10).

2 Baste recordar de su producción bibliográfica de los años setenta, la Historia de la Filosofía Latinoamericana (1979). 
comunidad. En el caso de Jaime Rubio, no puede tratarse, entonces, sino de una hermenéutica de lo latinoamericano en sus posibilidades de ser.

Hacia una hermenéutica de nuestra conciencia histórica privilegia en su análisis la autocomprensión posible que se produce frente al texto narrativo de ficción. El modelo explícito que Rubio acoge y cuyos frutos aquí presenta es el modelo de la triple mímesis de Paul Ricœur ${ }^{3}$, cuya exposición acabada encontramos en el primer volumen de Tiempo y narración (TR I).

Esta imponente trilogía de Ricœur despliega las posibilidades latentes de una presuposición mayor que guía toda la obra: "la apuesta última tanto por la identidad estructural de la función narrativa como por la exigencia de verdad de toda obra narrativa, es el carácter temporal de la experiencia humana" (TR I, p. 17)

Explicitemos esta presuposición. Aquí se avanzan dos enunciados a probar en Tiempo y narración: el primero afirma que toda narración, histórica o de ficción, tiene la misma estructura fundada en la intriga o trama narrativa (mythos) que tiene por finalidad la imitación (mímesis) de la acción humana ${ }^{5}$. Aquí, el dinamismo de la trama gobierna de tal modo los elementos de la acción humana que produce su convergencia profunda, su concordancia, en los diversos modos de narrar. Por su parte, el segundo enunciado sostiene que la exigencia de verdad opera tanto en la obra histórica como en la obra de ficción. Toda narración, como toda metáfora ${ }^{6}$ por lo demás, por su poder de innovación semántica, redescribe la realidad de tal modo que nos ofrece otro acceso a lo real y, por tanto, otra relación y otra dimensión de verdad, es decir, de conocimiento del mundo.

Estos dos enunciados se fundamentan en la presuposición de que la experiencia humana, como experiencia temporal, es imitable gracias al relato en tanto que este se configura como imitación de la acción humana. Ricœur reformula

3 Es incalculable la presencia del pensamiento de Paul Ricœur en la obra y en el magisterio de Jaime Rubio. Aquí simplemente señalamos el lugar que ocupa el modelo de la triple mimesis en Hacia una hermenéutica de nuestra conciencia histórica, sin agotar la pregunta por esta relación en otros textos de Jaime Rubio. Ver: Salinas Leal, 2005.

4 En este trabajo, las traducciones del francés de esta obra son mías.

5 Para la fundamentación en la Poética de Aristóteles, de esta teoría de la triple mímesis, véase: TR I, pp. 55-84.

6 Ricœur, 1975, pp. 273-321. 
esta presuposición en un círculo hermenéutico en el que la producción de sentido se da en la dialéctica siempre abierta y no totalizable entre tiempo y narración. En palabras del francés, "El tiempo se hace tiempo humano en la medida en que está articulado de manera narrativa; a su vez, el relato es significativo en la medida en que dibuja los rasgos de la experiencia temporal" (TR I, p.17).

El otro polo del libro de Rubio, sostenido por la presuposición ricœuriana, consiste en poner a prueba esta hipótesis y su explicitación teórica formulada en la teoría de la triple mimesis, investigando las relaciones entre tiempo y relato en la novela Cien años de soledad de Gabriel García Márquez.

El viaje que nos propone Rubio tiene, pues, al menos dos dimensiones convergentes. La menos ambiciosa pero fundacional en la arquitectura del texto, funge como introducción filosófica, es decir, creativa y creadora, al pensamiento de Paul Ricœur, en especial a su teoría de la innovación semántica como rasgo esencial de la metáfora y la narración en su producción de nuevos sentidos y de tramas, como mediación para la comprensión del hombre en su lenguaje. La vehemencia ontológica de metáfora y relato, su vínculo con la verdad, se explicita al mostrar que la metáfora describe unos rasgos de lo real (afectivos, estéticos, subjetivos) que el discurso directo no recoge; y, por su parte, el relato nos presenta un mundo esquematizado en la trama, como mundo posible, como mundo habitable.

El lenguaje poético debe su prestigio, dice Ricœur, a su capacidad de llevar al lenguaje aspectos de lo que Husserl llamaba Lebenswelt y Heidegger In-derWelt-Sein. Por ello, exige incluso que reconsideremos también nuestro concepto convencional de verdad, es decir, que dejemos de limitarla a la coherencia lógica y a la verificación empírica, de modo que tengamos en cuenta la pretensión de verdad vinculada a la acción transfiguradora de la ficción. No es posible seguir hablando de lo real y de la verdad -y sin duda alguna tampoco sobre el ser- sin haber intentado hacer explícitos previamente los supuestos filosóficos de toda la empresa. (Ricœur, 2000, p. 200)

Entonces, la teoría de la triple mímesis busca establecer la mediación entre temporalidad y narración de la acción humana. Su centro lo constituye la narración como puesta en intriga o como trama, el texto visto como síntesis unificadora de lo heterogéneo. La actualización de ese centro se produce en el acto de leer. Este centro como intriga dinámica corresponde al concepto de mímesis II. Sin embargo, en oposición a la aproximación estructural del relato, este está rodeado 
por un antes y un después del acto de leer. Y, en todo caso, siempre visto desde el acto de leer, lo que ya separa mímesis II de toda concepción estática del relato. El antes, identificado con el concepto de mímesis I es descrito como la precomprensión que tiene el lector de la acción humana, precomprensión que le permite seguir la historia propuesta en la trama. La mimesis I corresponde a la inteligencia narrativa que, antes de toda explicación del relato, nos permite anticipar la red conceptual, la lógica de la acción y sus recursos simbólicos puestos en marcha por la configuración narrativa. El después de la lectura corresponde al concepto de mímesis III, en el que el lector regresa a la vida y a la acción. Mímesis III, afirma Ricœur, "marca la intersección del mundo del texto y del mundo del auditor o del lector" (TR I, p. 136). Ese arco que va del antes, al durante, hasta el después de la lectura constituye el espacio de investigación de esta hermenéutica en la que la vida se cruza con el relato y sale transformada por él.

Por esta razón, ayer en la tarde no hubo un salto brusco en nuestro viaje filosófico narrativo entre las Cícladas y el Salto de Tequendama ${ }^{7}$. Si Teseo y Sócrates se hermanan en su búsqueda y vivencia de la vida justa y en su indiferencia a lo accesorio (un anillo o la cicuta); Kant y Humboldt se hermanan en su búsqueda y vivencia de la ciencia y la verdad, que en uno se expresa como sed de conocimiento en la inmovilidad de Königsberg y en el otro, en la preocupación de no dañar su barómetro en el arduo descenso al lecho del río Bogotá. Con todo, lo que aquellas ponencias suponían en profundidad e invitación al filosofar, en su diversidad se hallaba y se halla un espacio vital como lugar de convergencia: la comunidad de auditores en la atmósfera rigurosa y cordial de este Coloquio. Los mundos desplegados en la lectura se intersectan con este nuestro mundo vital de la filosofía aquí y ahora, entre nosotros y, à la limite, con las circunstancias históricas concretas en las que vivimos, actuamos y padecemos.

7 Mantengo también esta referencia puntual, situada en el contexto del XX Coloquio Interno de Profesores de la Facultad de Filosofía, pues no solo mantiene la unidad del texto sino que, además, funge como argumento para mostrar la fusión de horizontes o la mímesis III que se produce entre el horizonte del texto y el horizonte del lector en el momento de la lectura comunitaria de la comunicación a un auditorio. Aquí hago referencia a dos ponencias leídas en la tarde del 7 de octubre de 2015: «"Los dos veces siete”: Baquílides y el Fedón de Platón» del profesor Alfonso Flórez y «Kant, Humbolt y el Salto de Tequendama del P. Vicente Durán Casas, S.J. 
Así vista la tarea hermenéutica, el problema de la apropiación de los textos de la tradición se refigura como transformación constante e inacabada de la vida. El texto es un soporte que nos ofrece en la lectura opciones, es decir, posibilidades, para el ejercicio de nuestra libertad. "En definitiva, dice Rubio, si la lectura está apoyada sobre la mimesis del texto, esta solo se realiza plenamente cuando toma cuerpo en una existencia y en una libertad concreta" (Rubio, 2015, p. 14).

\section{El discurso filosófico como práctica y relato del pensar}

De allí Que Rubio defienda con radicalidad el valor teórico del relato: "Creo que los filósofos en nuestro medio debemos reconocer la legitimidad teórica del relato. No podemos seguir considerándolo como un "residuo" que no podemos evacuar; sino como una forma necesaria de la teoría de las prácticas" (Rubio, 2015, p. 15).

Por mi parte, y esta es mi hipótesis de lectura, creo que Rubio lleva a cabo dos movimientos de expansión teórica o, mejor aún, discursiva: de un lado, incluye la ficción y la historiografía en el campo de la filosofía como instancias de ese discurso que critica y subvierte el statu quo con lo que tiene de no realizado y de reprimido pero, del otro, hace del discurso filosófico una instancia del discurso narrativo y con ello lo incluye dentro de las posibilidades abiertas por la teoría ricœuriana de la triple mimesis.

Se trata de una hipótesis radical. Los relatos mismos en su diversidad son formas concretas de una práctica de producción del discurso en la sociedad, de la que esta misma obra que comentamos es un caso. Aquí Rubio, sin lugar a dudas, va más allá de Ricœur, articulando la teoría de la triple mímesis con la teoría de la narración de Michel de Certeau (2000, p. 87 ss.) en la que el relato es configuración teórica de las prácticas de una sociedad, de tal modo que el discurso filósofo puede entrar en el dominio de las prácticas narrativas como una de sus instancias.

En su artículo, “¿Cómo filosofar hoy?” (2005), Jaime Rubio hacía una afirmación que se sitúa en el horizonte de la hipótesis que aquí someto a la evaluación del lector: "La filosofía latinoamericana resulta ser una típica "narración" que es a la vez relato especulativo y relato emancipatorio, en particular en cuanto se nos presenta como un saber histórico o como un filosofar sobre nuestra historia” (Rubio, 2005, p. 23). 
El pasaje determina el modo de hacer filosofía en América Latina como una forma de narración especulativa, conjugando los elementos propios del discurso filosófico con los de la narración histórica. La consecuencia es manifiesta, la filosofía como discurso se inscribe en la dinámica de la triple mímesis. En un momento retomaré esta hipótesis.

Por ahora volvamos sobre las nociones de "mundo del texto" y "mundo del lector". "La noción "mundo del texto", afirma Rubio, es la categoría que marca la ruptura ricœuriana en la hermenéutica contemporánea” (Rubio, 2015, p. 29). En efecto, lo que buscamos en el texto no es ni la psicología ni el pensamiento de un autor, su subjetividad cristalizada en el relato. No nos interesa el autor o su pensamiento. Por el contrario, buscamos en el texto la experiencia de un mundo posible que se despliega en el acto de leer como mundo de los agentes y pacientes del relato. Por su parte, el "mundo del lector" es ese horizonte mudo en el que vivimos, actuamos y padecemos y desde el que poseemos las claves para seguir una historia e interpretarla haciéndola nuestra. "Comprendiendo una nueva posibilidad de habitar el mundo, dice Rubio, es como recibo una nueva posibilidad de existir y de comprenderme yo mismo" (Rubio, 2015, p. 29).

Varias apuestas se derivan de esta tarea hermenéutica. La universalidad transcultural de la narración. La expansión de la realidad y, por lo tanto, de la verdad más allá de lo empírico. El valor ético y político de narrar y de leer las narraciones. El valor, tan caro a Ricœur y a Rubio, de la esperanza como posibilidad de lo aún no sido, latente en nuestra historia narrada. ¿Por qué narramos, entonces? Para conservar lo memorable (que puede estar asociado al horror, a lo terrible) y para liberar las potencialidades del presente, para actualizar lo que no fue y aún puede ser. Es así que la narración no apunta a la comprensión exclusiva de ese mundo que se despliega en el texto, sino al futuro y a las iniciativas del lector.

De esta tarea se deriva la noción de identidad narrativa como identidad abierta a la historicidad de la vida y al conocimiento de la tradición y de la historia personal y colectiva en un círculo dinámico entre la acción y la lectura como acción reflexiva. La identidad narrativa se sitúa entre la identidad esencial del idealismo trascendental y la disolución del sujeto ya presente y operante en Nietzsche ${ }^{8}$.

Ricœur, 1990. 
Sobre este suelo se construye la lectura que Jaime Rubio nos ofrece de Cien años de soledad como "discurso teórico de nuestros procesos históricos subversivos" (Rubio, 2015, p. 16). Pues si la literatura es subversiva, lo es por su capacidad de redescribir la realidad y exhibir lo no dicho de la historia, otras posibilidades de habitar el mundo. No voy a entrar en la exposición analítica de esta lectura, de esta apropiación que Rubio nos presenta de Cien años de soledad. No lo hago fundamentalmente por una falta de competencia que alimenta mi pudor'. Sin embargo, puedo adelantar a sus futuros lectores, que la valoración de la obra conduce a Rubio a separarse de la interpretación canónica, introducida por Mario Vargas Llosa, según la cual el tiempo ciclo gobierna la intriga de la novela. Para Rubio (2015), Cien años de soledad es la novela de "un siglo en un instante" (pp. 73-99).

Habrá que leer y releer a Rubio y a García Márquez para medir la profunda renovación que esta lectura de nuestro clásico puede llegar a representar. Pero, de nuevo, esta lectura de Rubio se sitúa en la lógica ricœuriana de la transformación de sí. "En efecto, lo que recibo, nos dice Rubio, nuestra herencia, son las posibilidades, nuestros proyectos" (Rubio, 2015, p. 115). En ese sentido, la tradición asumida se hace iniciativa, deseo de hacer la historia, libertad y futuro.

Por esta razón, interpreto la preposición hacia, que por feliz intuición de los editores determina el título de la obra, como indicación de la dirección y el movimiento de una tarea que no se quiere acabada o cumplida, porque se sabe siempre abierta. Tarea posible, tarea futura.

No puedo evitar compartir con ustedes esa sensación de haber entendido, muchos años después, algunas de aquellas sentencias oraculares y de alusiones que poblaban las clases de Jaime. Su interés filosófico por la historia y la literatura, sus referencias a la actualidad (de los diálogos del Caguán a la vida de la Facultad), su insistencia por la distinción entre balón y esfera ${ }^{10}$, y por renunciar a Hegel, a la totalización, a cambio de una mediación imperfecta en una dialéc-

9 Sobre este punto remito a la contribución que el profesor Leonardo Tovar presentó en el homenaje a Jaime Rubio en el marco del XX Coloquio interno de profesores de la Facultad de Filosofía el 8 de octubre de 2015.

10 En el mundo precientífico de la vida no hay esferas, solo balones, pelotas, bolas. No hay un tiempo segmentado en unidades discretas, sino una experiencia que se extiende sobre su espacio de experiencia y su horizonte de espera en un tiempo humano, es decir, histórico. La esfera pertenece al 
tica abierta. Cada gesto se inscribía, así los veo hoy, como parte de ese círculo hermenéutico de la triple mímesis que él hizo vida.

En este punto retomo la hipótesis de lectura a propósito del estatuto de ese discurso filosófico-narrativo que quiere ser Hacia una hermenéutica de nuestra conciencia histórica y, a fortiori, el discurso filosófico en la obra de Jaime Rubio. Por su arquitectura y su intención, en Rubio se halla la unidad de un pensamiento que se acepta situado y en mediación hacia su autocomprensión por la vía de la apropiación de las obras de la cultura, y en este caso, por el relato de ficción encarnado en Cien años de soledad. Sin embargo, cada tanto me pregunto si en la práctica filosófica de Jaime Rubio, en sus clases como en sus obras, y en especial en esta, no se exige del discurso filosófico y del filósofo lector, lo mismo que Ricœur presenta como constitutivo de la dialéctica entre relato y tiempo para el relato de ficción.

En efecto, el estilo de la obra, como Rubio (2015, p. 15 ss.) lo afirma en las primeras páginas de la obra, corresponde a una modalidad de las "maneras de hacer", de las "prácticas", como las entiende Michel de Certeau, para quien la reivindicación de la narración como teoría de las prácticas tiene un doble efecto: que la narración sea la modalidad bajo la cual se piensan las prácticas humanas y que la narración misma sea una práctica, la de pensar las prácticas mostrándolas en la acción narrada. Así, la narración es una instancia de las prácticas y su propia teoría. En otros términos, la teoría de las prácticas no puede ser distinta a la narración de las prácticas en sus múltiples instancias. "Si el arte de decir es en sí mismo un arte de hacer y un arte de pensar, puede ser a la vez su práctica y su teoría” (de Certeau, 2000, p. 87 ss.).

No nos resulta difícil entender y aceptar que el discurso filosófico sea la teoría de la práctica filosófica, que su teoría y su práctica se fundan en el discurso filosófico mismo. Pero sí nos resulta difícil pensar que el discurso filosófico funcione, en el sentido de Paul Ricœur, narrativamente. Pero eso es precisamente lo que piensa Rubio de la mano de Michel de Certeau, en la medida en que el discurso filosófico cumple una función propia a nuestra situación, como discurso emancipatorio. En palabras de Rubio (2015): "Nosotros mismos constituimos un campo de experimentación y elucidación de las prácticas de poder que funcionan como prácticas

orden de la geometría. El tiempo discreto pertenece al orden de la física. Al respecto, véase: Ricœur, TR III, pp. 374-433. 
intelectuales ${ }^{11}$, pensamos que al denunciarlas podemos inventar formas de pensar diferentes" (p. 15).

Y aunque este punto es fundamental y deberá ser profundizado en una lectura e interpretación de mayor calado, esta caracterización del estilo de la obra me invita a ver en las clases que Jaime Rubio impartía y en este libro, por no mencionar el conjunto de su obra, una intención explícita por activar la operación interpretativa del oyente y del lector, gracias a un discurso que se ofrece indicativo y poético menos que puramente expositivo, sugestivo menos que analítico, oracular a veces menos que argumentativo. Un discurso que pide por opción metodológica y, por ende filosófica, ser interpretado como un relato filosófico.

En otros términos, tengo la impresión de que esa pregunta insidiosa que hacía Jaime cada tanto en sus clases, «¿Qué van a hacer ustedes con esto?», -siendo esto el texto de la Metafísica o de la Crítica de la razón pura, por ejemplo-, era su invitación a veces furiosa y a veces desesperada para que pasáramos de la lectura de un texto y de la audición de una clase, siempre difícil, a la iniciativa y a la acción interpretativa, es decir, a la acción vital. Creo, pues, que se trataba de una invitación para que recorriéramos el círculo hermenéutico entre tiempo y narración, teniendo como eje, ya no la configuración narrativa, sino el discurso filosófico leído como un relato.

\section{A manera de conclusión}

COMO LO MENCIONÉ UN POCO MÁS ARRIBA, creo que aquí Rubio va más allá de Ricœur, articulando la teoría de la triple mímesis a la teoría del relato de Michel de Certeau. ¿Cómo? Creo que Rubio asumía la tarea de la lectura filosófica en tanto interpretación del discurso filosófico, como Ricœur asumía la de la narración. Es decir, creo que para Rubio la teoría de la triple mímesis podía aplicarse también a la lectura del discurso filosófico. Como todo lector lo sabe, Ricœur no llegó a sostener la tesis de la identidad entre discurso filosófico y narración.

11 Corrijo el original "prácticas de intelectuales" que no parece corresponder con el sentido del pasaje, por “prácticas intelectuales”, en el sentido de distinguir el tipo de práctica de su productor. 
Por el contrario, Ricœur veló siempre por mantener la autonomía del concepto frente a la metáfora y la narración ${ }^{12}$.

Rubio solo pudo dar este paso suplementario de la mano de Michel de Certeau. Y lo dio en dos direcciones. La primera, retomando la reivindicación del relato como teoría de las prácticas. Y, la segunda, afirmando que su propia obra Hacia una hermenéutica de nuestra conciencia histórica, funda su estilo filosófico en las maneras de decir que tematiza de Certeau. En otras palabras, para Rubio, su libro pertenecería tanto al orden del discurso filosófico como al espacio de los relatos filosóficos, que para él son uno solo.

$\mathrm{Al}$ articular a Ricœur con de Certeau, Rubio cubre novedosamente dos aspectos que preocupan desde siempre a la hermenéutica: el lugar de producción del relato y el mundo que este despliega. Con Michel de Certeau, el relato es la teoría de las prácticas (de la acción humana en su diversidad y cotidianidad) y la práctica de una teoría (la escritura como práctica discursiva y como ejercicio del pensar). Así vista, la narración tiene en efecto un autor, pero el peso de la interpretación recae sobre lo que la práctica expuesta en la narración nos muestra y no en lo que el autor quiso decirnos. El pensamiento del autor se concreta como práctica de la escritura filosófico-narrativa. Con Ricœur, en la misma línea, el texto despliega un mundo que se actualiza en el acto de leer y en la vida de lector. Lo que leemos es un mundo posible, un mundo habitable, que nos impulsa de nuevo a la acción que es, a un tiempo, interpretación, pensamiento, vida y libertad concreta.

\section{Referencias}

Arias, C. et al. (2015). Nota editorial. Hacia una hermenéutica de nuestra conciencia histórica. Bogotá: Editorial Pontificia Universidad Javeriana. Colección Anábasis.

de Certeau, M. (2000). La invención de lo cotidiano: I. Artes de hacer. México, D.F.: Universidad Iberoamericana e Instituto Tecnológico y de Estudios Superiores de Occidente.

12 Ver: Ricœur, 1975, pp. 323-399. 
Ricœur, P. (2000). Narratividad, fenomenología y hermenéutica. Anàlisi, 25, pp. 189-207.

Ricœur, P. (1990). Soi-même comme un autre. Paris: Seuil.

Ricœur, P. (1985). Temps et récit. III. Le temps raconté. Paris: Seuil.

Ricœur, P. (1983). Temps et récit. I. L’Intrigue et le récit historique. Paris: Seuil. $(T R \mathrm{I})$

Ricœur, P. (1975). La Métaphore vive. Paris: Seuil.

Rubio, J. (2015). Hacia una hermenéutica de nuestra conciencia histórica. Bogotá: Editorial Pontificia Universidad Javeriana. Colección Anábasis.

Rubio, J. (2005). ¿Cómo filosofar hoy? Universitas Philosophica, 22(44-45), pp. 19-37.

Rubio, J. (1979). Historia de la Filosofía Latinoamericana. Bogotá: USTA-Centro de Enseñanza Desescolarizada.

Salinas Leal, H.H. (2005). El deseo de una filosofía narrativa: Jaime Rubio lector de Paul Ricœur. Universitas Philosophica, 22(44-45), pp. 141-153. 